\title{
Assentamentos Rurais em São Paulo: Estratégias e Mediações para o Desenvolvimento
}

\author{
Luís Antonio Barone \\ Vera Lúcia S. Botta Ferrante
}

\section{INTRODUÇÃO: EXPLICITANDO A PERSPECTIVA ANALÍTICA}

$\mathrm{E}$ ste trabalho busca avaliar as ações e políticas pró-desenvolvimento dos assentamentos rurais em duas regiões bastante diferenciadas do Estado de São Paulo: Pontal do Paranapanema e Araraquara. Objetiva-se estudar os agentes e as agências que se defrontam no campo de disputa dessas políticas, campo de forças gerador de tensões, conflitos, resistências e acomodações, dando especial foco aos mediadores oficiais e políticos da reforma agrária (órgãos públicos de terras e organizações de trabalhadores). Pode-se considerar que a trajetória e os destinos das experiências de assentamentos e dos trabalhadores assentados se moldam a partir da dinâmica, de impasses e bloqueios gerados, muitas vezes, no interior dessas agências.

Esse exercício sintético faz parte de um esforço de pesquisa e análise de mais de duas décadas ${ }^{1}$, no qual se buscam elucidar os impasses nas trajetórias dos assentados, sustentados pela reavaliação e reapropriação das medidas institucionais, pelas tentativas de mudança de rumos nas suas vidas, mesmo nos casos mais extremos, como o arrendamento de suas terras (Martins, 2003) e pelo redirecionamento de algumas ações dos mediadores que, com frequência, se pautam por modelos acabados e simplistas (Martins, 2000), contrariando a diferenciação e a

DADOS - Revista de Ciências Sociais, Rio de Janeiro, vol. 55, nº3, 2012, pp. 755 a 785. 
multidimensionalidade dos processos de assentamentos rurais (Ferrante, 1992).

Discute-se que o confronto desses atores - os próprios trabalhadores, suas organizações representativas e os responsáveis oficiais pela política de assentamentos - nos espaços sociais de disputa e constituição das políticas públicas é gerador de uma trama de tensões, opondo interesses e racionalidades diversas, mediante distintos projetos, compromissos e estratégias. O desenvolvimento das experiências de assentamentos se dá, então, na sua trajetória, frente aos constrangimentos estruturais que a sociedade impõe, sobretudo através do mercado e do Estado, como também frente à necessária reelaboração da própria trajetória pessoal e familiar desses novos sujeitos, os assentados (Barone e Ferrante, 2011).

Não existem, da parte de todos os agentes que se movimentam neste campo específico, projetos claramente definidos e opostos. O próprio Estado e seus representantes claudicam no encaminhamento das políticas para os assentamentos, muitas delas criadas no empuxo das mobilizações dos trabalhadores rurais. Isto não significa que embates concretos não aconteçam, animando o campo político criado a partir da implantação dos assentamentos e dos dilemas de sua gestão. Tais embates seriam a resultante mais conflituosa de um conjunto de tensões sociais geradas pelas relações entre os distintos agentes que se põem e dispõem nesse campo.

Neste artigo, procede-se a uma síntese de informações, colhidas no âmbito do Núcleo de Pesquisa e Documentação Rural (Nupedor) desde os anos 1980, numa tentativa de compreender os condicionantes da reforma agrária em São Paulo, sob uma perspectiva qualitativa que ressalta os contextos e os processos políticos a ela subjacentes. Os dados apresentados, quando não referenciados em trabalhos já publicados, foram levantados durante anos de monitoramento e diálogo, junto às agências de mediação analisadas.

Diante da limitação de espaço para inúmeros esclarecimentos, recorre-se a notas de rodapé, sempre que necessário. Longe de ter um caráter normativo, o texto procura oferecer uma leitura crítica da realidade, de modo a revelar as tramas de tensões (Barone e Ferrante, 2011) produzidas pela dinâmica dos agentes em questão, uma opção metodológica julgada capaz de dar conta da riqueza do objeto estudado. 
Em meio a todos esses agentes, os trabalhadores beneficiários nos projetos de reforma agrária se apresentam, muitas vezes, em posição de subalternidade, porém com um relativo poder de barganha e de controle frente aos mediadores. Diante das forças do mercado local/ regional ou das imposições mais genéricas do Estado, esses trabalhadores buscam desenvolver estratégias ou iniciativas que permitam sua manutenção na terra, embora esse objetivo maior comporte práticas contraditórias que, em última instância, podem levar a uma direção exatamente oposta. Este é o caso da alternativa de trabalhar fora do assentamento, situação que pode prenunciar o abandono do local, a médio e longo prazo.

A possível integração ${ }^{2}$ do assentado, enquanto produtor, nos circuitos econômicos que dinamizam o mercado local/regional apresenta-se problemática. Os territórios dos assentamentos apenas parcialmente atendem às exigências desses circuitos, quando não se apresentam muito distantes do padrão dominante de acumulação econômica dos respectivos contextos regionais. Falamos de bloqueios dessa integração quando os assentamentos não reúnem condições para a alocação adequada dos fatores produtivos - como é o caso dos financiamentos e assistência técnica - ou quando os mercados locais/regionais não oferecem agentes econômicos dispostos a distribuir a sua produção. O assentado se vê, em muitas das situações, reduzido a um produtor de excedentes numa economia altamente mercantilizada e (dependendo do contexto regional) também bastante capitalizada. Em outras vezes, o assentado passa a ser protagonista de medidas institucionais recentes, relativas à obrigatória inserção da produção local regional na merenda escolar, por força da legislação federal, não necessariamente cumpri$\mathrm{da}^{3}$.

Dados os patamares de desenvolvimento econômico das diferentes regiões em estudo - Araraquara e Pontal do Paranapanema -, sobressai, em primeiro plano, a inserção dos assentamentos no circuito de fornecedores de cana-de-açúcar para as agroindústrias. Essa modalidade de produção passou a ser normatizada pela Fundação Instituto de Terras do Estado de São Paulo (Itesp), qualificada como "parceria negocial" entre assentados e agroindústrias, a partir de 2002, com significativa adesão dos assentados da região de Araraquara. Porém, a produção de cana para fornecimento às agroindústrias manteve-se proibida nos assentamentos sob jurisdição do Instituto Nacional de Colonização e Reforma Agrária (Incra), gerando uma ambiguidade no tratamento da 
questão pelos órgãos oficiais, além de uma viva polêmica sobre a adequação desse cultivo nos assentamentos.

O que poderia ser a solução para os bloqueios do desenvolvimento econômico dos assentamentos tem-se revelado cheio de impasses, nos quais uma insegura melhora na renda monetária oculta a possibilidade de perda de autonomia na gestão do lote e, na medida em que essa modalidade de "parceria" acaba por caracterizar-se como arrendamento - como é o caso dos assentamentos federais -, até mesmo a perda do lote, via exclusão oficial (Barone, Ferrante e Bergamasco, 2008).

Por outro lado, o nível inferior de capitalização em geral, na região do Pontal, aproxima o assentado, geralmente um produtor de leite, de muitos outros produtores que são pequenos proprietários. Esta equivalência, no entanto, não resolve o dilema de baixa remuneração na atividade, aliás, comum nos dois grupos. A melhora advinda de algumas ações oficiais de apoio à produção leiteira, não cria uma situação segura de rentabilidade para os assentados. As alternativas de melhoria da renda e agregação de valor, através de organizações de produtores assentados não demonstram lograr sucesso em ambas as regiões, 0 que demanda uma reflexão acerca de estratégias de formação de associações e cooperativas, no mais das vezes estimuladas por políticas e agências oficiais, como também pelas organizações de trabalhadores (MST, sindicatos e outros).

Nesse aspecto, também é evidenciada a diferenciação entre grupos de assentados e suas estratégias de geração de renda, organização de trabalho e representação política. A partir de um conhecimento empírico acumulado que já se tem, como o dos produtos destinados ao consumo familiar, organizam-se formas de geração de trabalho e renda, ainda timidamente apoiadas por agências oficiais, o que resulta numa diversificação, também, de tais estratégias, diferentes daquela de integração às agroindústrias.

Num primeiro nível de mediação, consideramos as próprias organizações dos assentados, notadamente as associações (Barone et alii, 2008), sempre presentes nos assentamentos. As organizações cooperativas, um segundo nível de mediação, são estruturalmente mais complexas e, no geral, estão sob controle direto das organizações políticas que têm os trabalhadores assentados como base. É assim nos contextos regionais estudados, casos da Cooperativa de Comercialização e Prestação de Serviços dos Assentados da Reforma Agrária no Pontal (Cocamp) e 
Cooperativa de Produção de Biodiesel do Oeste Paulista (Cooperbioeste) (Pontal) e Cooperativa Unificada dos Trabalhadores do Campo (Unicampo) (Araraquara) ${ }^{4}$, que ora se apresentam com algum grau de proximidade do cotidiano dos assentados, ora propõem ações e se movimentam com um alto grau de externalidade aos assentados, revelando a complexidade e o estranhamento dessas organizações. As descontinuidades e perspectivas das associações e cooperativas contam efetivamente na análise dos rumos dos assentamentos rurais (Barone et alii, 2008).

O terceiro nível é o dos mediadores oficiais, entendidos como os agentes públicos, sejam os de perfil técnico (como agrônomos) ou político (representantes dos poderes públicos locais e regionais). Estes mediadores têm a formulação de políticas de desenvolvimento dos assentamentos ao seu encargo, mas, muitas vezes, atuam como impedimentos às alternativas mais autônomas dos trabalhadores. Neste artigo, dá-se especial destaque para as agências públicas de mediação - em São Paulo, os órgãos de terras: Itesp e Incra -, bem como para a trajetória recente (no governo Lula) dos principais mediadores da luta pela terra nas duas regiões paulistas: Movimento dos Trabalhadores Rurais Sem-Terra (MST) e a Federação dos Empregados Rurais Assalariados do Estado de São Paulo (Feraesp), sobretudo em sua relação com os governos.

Este esforço de síntese busca estabelecer relações possíveis entre uma dada realidade empírica, que é mais que uma política pública, porque é também obra da luta de milhares de famílias camponesas e um conjunto de preocupações teóricas daqueles que estudam ou interferem, via Estado, nessa realidade. A gestão que os assentados imprimem ao território dos assentamentos, nos aspectos da sua organização social, sua mobilização e instituições políticas e sua participação econômica, pode redundar em mais ou menos liberdade para essas famílias (Sen, 2000). O desenvolvimento, dessa forma, se dá na trajetória dessas experiências de reelaboração da própria trajetória pessoal e familiar desses novos produtores familiares e sua participação (tensionada/tensionadora) nos campos da política e da produção.

\section{OS ASSENTAMENTOS EM DISTINTOS CONTEXTOS: DIVERSIDADES REGIONAIS E CONJUNTURA POLÍTICA}

Como um estudo que se propõe a avaliar a implantação e a gestão das políticas de desenvolvimento para os assentamentos rurais, a partir da mobilização dos agentes que compõem esse campo específico, pesqui- 
saram-se duas regiões do Estado de São Paulo: 1) a região central do estado, com destaque para os assentamentos da microrregião de Araraquara; 2) o Pontal do Paranapanema, região localizada no extremooeste paulista. Nelas, a ação pública para o assentamento de famílias de trabalhadores rurais tem intensidades diferentes, tornando difícil uma comparação stricto sensu.

As características socioeconômicas das distintas regiões em estudo revelam uma grande disparidade em termos de desenvolvimento regional. Enquanto a região central do estado apresenta índices de dinamismo econômico notáveis, a região do Pontal do Paranapanema tem um diagnóstico de "esvaziamento econômico", em favor das regiões fronteiriças de Mato Grosso do Sul e Paraná (Barone e Ferrante, 2010).

O caráter comparativo deste estudo visa, então, ressaltar os possíveis destinos das experiências de assentamentos, em função das tramas sociais constituídas pelos distintos conjuntos de agentes / atores políticos que animam o cenário regional em cada caso, bem como através das tensões que se expressam no campo das alternativas políticas e econômicas. Assim, pecuaristas ligados à União Democrática Ruralista (UDR) no Pontal e empresários agroindustriais ligados ao setor canavieiro na região de Araraquara são agentes que apresentam posições simétricas no campo de forças em estudo, mas que não têm, necessariamente, a mesma estratégia, frente às tensões geradas a partir do desenvolvimento dos assentamentos.

A microrregião de Araraquara, na área central do Estado de São Paulo, conta com três projetos de assentamentos rurais (PAs), produtos de diferentes políticas públicas gestadas ao longo dos últimos 25 anos. Dois deles são de responsabilidade do Instituto de Terras do Estado/Itesp (Monte Alegre e Horto Bueno de Andrade), e um do Incra (Bela Vista do Chibarro). Os primeiros núcleos de assentamentos (Monte Alegre I, II, III e IV) foram instalados pelo Itesp nos anos de 1985 e 1986, em áreas da extinta Ferrovia do Estado de São Paulo (Fepasa), ainda na gestão do governador Franco Montoro (1983-1986), tendo sua instalação se completado quase dez anos depois. Hoje, o Projeto de Assentamento Monte Alegre conta com seis núcleos, perfazendo um total de 416 lotes agrícolas. São 418 famílias que ali residem, segundo dados da Fundação Itesp ${ }^{5}$. Além desses núcleos do Itesp, existe um PA promovido pelo governo federal (Incra) no município de Araraquara: o PA Bela Vista do Chibarro, com 176 lotes agrícolas e cerca de 210 famílias. Este assen- 
tamento se encontra em terras anteriormente pertencentes a uma usina de açúcar (Usina Tamoio), cuja desapropriação data de 1989.

O Pontal do Paranapanema e sua série de irregularidades em relação aos títulos de propriedade das terras, somada à grande ociosidade na utilização das áreas desmatadas, têm assistido, desde há muito, a conflitos e lutas pela posse da terra. À supracitada insegurança fundiária e à ação que os governos do período da transição democrática desenvolveram, através de uma tímida política de assentamento, os diferentes agentes sociais dessa região responderam com mobilizações, de ampla divulgação na década de 1990.

Já no primeiro ano do governo Collor (1990), o MST iniciou o seu mais importante processo de luta pela terra no estado (Fernandes, 1996). A partir de então, o conflito entre os sem-terra - tendo o MST como a sua organização mais ativa e representativa - e os fazendeiros pecuaristas, liderados pela UDR, tem pontuado a história da região. Centenas de ocupações, milhares de trabalhadores mobilizados e acampados, dezenas de ações judiciais discriminatórias promovidas pelo estado no sentido de identificar e arrecadar as terras devolutas irregularmente ocupadas: esse é o contexto sociopolítico do Pontal ${ }^{6}$. Nesse cenário, o incremento da política de assentamentos na região aconteceu, sobretudo, na primeira gestão do governador Mário Covas (1995-1998), como resultado de intensas negociações para arrecadação de áreas e o assentamento de milhares de famílias. O Pontal do Paranapanema é, hoje, a região paulista com o maior número de assentamentos e de famílias assentadas.

Em que pesem as conjunturas e as configurações políticas dos órgãos públicos responsáveis pelos assentamentos, a própria política de assentamentos obedeceu a estratégias governamentais distintas. Enquanto em Araraquara essa ação reformista teve início como uma resposta às mobilizações dos assalariados rurais, após as greves de Guariba, nos anos 1984-1985 (Barone, 1996) e objetivou, no mais das vezes, áreas públicas do patrimônio da extinta Fepasa, no Pontal, região marcada pela ocupação fundiária irregular, o estado realizou ações pontuais voltadas para o assentamento de posseiros (e reassentamento de ribeirinhos), até o período mais recente, quando a pressão dos movimentos de trabalhadores rurais teve, como contrapartida, a instalação de dezenas de projetos de assentamentos em áreas consideradas devolutas. 
Claro que a conjuntura política e as forças sociais que conseguiram, mesmo que episodicamente, fazer valer seus interesses na esfera governamental, muitas vezes são as mesmas que incidiram sobre a política de assentamentos nessas duas regiões. Assim é, que a abertura política dos anos 1980, com o fervilhar das demandas sociais e políticas reprimidas, está diretamente relacionada com a instalação dos primeiros núcleos de assentamentos nas terras do horto de Silvânia (PA Monte Alegre) e com a implantação do maior assentamento do Pontal (a Gleba XV de Novembro, entre os municípios de Rosana e Euclides da Cunha). Nesse período, durante o governo André Franco Montoro (1983-1986), todo um arranjo institucional foi montado, com vistas a instrumentalizar uma ação reformista por parte do governo do Estado de São Paulo (Barone, 1996).

Da mesma forma, uma ação mais intensa por parte do governo estadual voltou a ocorrer em meados da década de 1990 (governo Mário Covas). Paralelamente a um programa de arrecadação de terras para assentamentos no Pontal, região mais conflitada do período, o Itesp buscou reorganizar sua atuação e garantir apoio para setores até então desprezados, como os remanescentes de quilombos. Na região de Araraquara, durante o governo Covas, a totalidade das terras da Monte Alegre passou a abrigar assentamentos e hoje, são seis núcleos ali instalados.

Neste início do século XXI, a atuação do órgão de terras estadual não logrou manter o ritmo de assentamentos no Pontal. Além disso, a publicação, em finais de 2002, da portaria do Itesp que autoriza o que denomina de "parcerias negociais" dos assentados com agroindústrias na prática, uma aceitação da polêmica implantação do cultivo de cana-de-açúcar para fornecimento às usinas - revela, claramente, uma inflexão na orientação política do órgão estadual, até então resistente às seguidas propostas de consórcio e/ou parceria com usinas de açúcar e álcool que foram discutidas ao longo dos anos 1990 (Ferrante e Santos, 2003).

O contexto político nacional também rebate de forma mais ou menos uniforme nas regiões em estudo. O governo Lula, iniciado em 2003, precisou responder às demandas e expectativas dos setores reformistas que o apoiaram. Em São Paulo, o Incra, frequentemente tido como ausente pelos assentados em projetos federais, descentralizou, nesse período, sua atuação e ampliou - sobretudo via terceirização - seu 
quadro técnico. Destaca-se, também, nesse movimento de fortalecimento do Incra, a instalação de alguns assentamentos federais no Pontal do Paranapanema, região na qual a ação institucional do Itesp sempre foi mais marcante.

\section{OS MEDIADORES OFICIAIS: OS ÓRGÃOS DE TERRAS EM DISTINTAS CONJUNTURAS}

A constatada ineficiência na mediação das políticas públicas para os assentados é notória e já discutida (Barone, 2000; Martins, 2003; Ferrante e Barone, 2004). Essa mediação, que tem nos agentes técnicos do estado ou contratados, e nas organizações de trabalhadores sua principal realidade social, sofre com diferentes formas de carências. A primeira delas, notadamente no campo da assistência técnica e extensão rural, é a insuficiência de estrutura e recursos (humanos e financeiros) para o atendimento das reais demandas dos assentados. Destaca-se, neste aspecto, a alternância de períodos com maior ou menor investimento político e, portanto, financeiro, nas agências de assistência técnica e extensão rural (ATER ou ATES).

Considerando a existência de dois órgãos públicos de terras, às vezes rivais, atuantes no estado, constata-se a alternância de iniciativas, de acordo com o governo de turno. Assim é que Incra ${ }^{7}$ e Itesp poucas vezes tiveram uma forte sincronia e cooperação. Tal discrepância já existia, embora um tanto velada, nos períodos em que União e estado tinham governos do mesmo partido - período José Sarney/Franco Montoro-Orestes Quércia, de 1985 a 1989; e Fernando Henrique Cardoso/Mário Covas-Geraldo Alckmin, de 1995 a 2002. A partir da ascensão do Partido dos Trabalhadores (PT) ao governo federal, e considerando a manutenção dos governos do Partido da Social Democracia Brasileira (PSDB) em São Paulo - a partir de 2003 - as desavenças passam a ter flagrante visibilidade, ganhando nitidamente a dinâmica de disputa partidária entre oposição e situação nos dois níveis de governo.

No entanto, além da circunscrição das ações dos órgãos de terras às políticas de governos com orientações partidárias distintas, foram especialmente notáveis as mudanças havidas na condução do Itesp. A cada período de governo estadual, mesmo que se considere a sucessão das alianças situacionistas, tanto nos anos 1980/1990 (Montoro, Quércia e Luiz Antônio Fleury, do PMDB), quanto nos períodos Fernando Henri- 
que Cardoso, Luiz Inácio Lula da Silva e Dilma Rousseff (governos Covas, Alckmin, José Serra e, novamente, Alckmin, todos do PSDB) ${ }^{8}$, foram nomeados vários diretores executivos do Itesp.

A explicação para mudanças, por vezes drásticas, na orientação política do Itesp, apesar de inalteradas as alianças que sustentam os governos estaduais em pelo menos dois longos períodos, tem na conjuntura econômica do país (e nas finanças dos governos estaduais) uma causa relevante. Mesmo assim, São Paulo experimentou momentos de maior ou menor ação reformista de seus governos, através de seu órgão de terras, apesar do longo período de crise econômica e limitações orçamentárias do ente público estadual durante todos os anos 1980 e boa parte dos anos 1990.

Por outro lado, o período de maior inação do Itesp corresponde justamente ao de maior incremento econômico do país nas últimas décadas (entre o final do primeiro e durante o segundo governo Lula, durante as gestões Alckmin e Serra ${ }^{9}$ ). Sem dúvida, o alegado esvaziamento da pressão popular por reforma agrária, em função do crescimento da oferta de emprego e das demais políticas compensatórias no período, tem um peso a ser ponderado, não eximindo, no entanto, os últimos governos estaduais de terem adotado uma postura de fraca atuação na política de assentamentos. Isso se torna particularmente flagrante no governo Serra, no qual o Itesp sofre um denunciado esvaziamento político. A existência de ações no período se deu quase que por inércia, já que "fechar o órgão" implicaria ônus políticos e orçamentários de grande monta ${ }^{10}$.

Retrospectivamente, um claro somatório de motivação política e conjuntura econômica extremamente favorável, fez com que o governo Mário Covas, notadamente em seu primeiro período (1995-1998), levasse a cabo uma política de assentamentos que atendeu a milhares de famílias sem-terra, com forte atuação (embora não restrita) na região do Pontal do Paranapanema. Ali, o contexto econômico de paridade cambial e abertura comercial, que ampliou as importações de alimentos como carnes e leite, levou a uma severa crise financeira no setor agropecuário. A chamada "âncora verde do real"11 prejudicou o setor pecuarista da região do Pontal (o de maior absorção de terras), cujos produtores ainda enfrentavam a forte mobilização de sem-terra liderada pelo MST. 
A chegada de Covas ao governo estadual naquela conjuntura foi uma oportunidade ímpar para que o estado lograsse arrecadar, mediante pagamento em dinheiro, milhares de hectares na região, já então reconhecida como ocupada através de sucessivas grilagens ${ }^{12}$. Os pecuaristas, muitos deles inadimplentes, assistiam às reiteradas ações de ocupação e acampamento nas fazendas. Mesmo a reação da UDR, fortemente implantada na região, não conseguia fazer frente ao MST. A possibilidade de negociar com o governo estadual o pagamento à vista das benfeitorias por eles implantadas, num momento em que crescia uma opinião pública favorável à reforma agrária nas "terras devolutas do Pontal", foi irresistível para muitos fazendeiros endividados.

Paralelamente a essa ação de arrecadação de terras, o governo Covas reestruturou seu órgão de terras. Ressalta-se, aí, um empenho de requalificação do corpo técnico, com seminários, minicursos e até mesmo a organização de uma revista do Itesp (os Cadernos do ITESP), sem dúvida um avanço de reflexão e organização de fontes e arquivos. É desse período, também, como fruto desses seminários realizados com acadêmicos, a organização de diretrizes para a assistência técnica rural executada pelo órgão, evidenciando a consciência de se ter um marco orientador para a ação dos técnicos (Barone, 2000).

Tais iniciativas, se não superaram limitações do órgão, como o crônico déficit de recursos humanos para a ATER, dotaram o Itesp de um grande poder de interlocução com os movimentos e organizações de trabalhadores rurais. A implantação de uma diretoria de mediação de conflitos e formação de equipes para atuar junto à população remanescente de quilombos fortaleceram, sobremaneira, o Itesp, um claro sinal da orientação do governo Mário Covas, um quadro político comprometido com a bandeira da reforma agrária ${ }^{13}$.

O afastamento de Mário Covas em 2000, motivado pela doença que o levaria à morte (2001) durante a vigência de seu segundo mandato (1999-2002), levou ao comando do governo seu vice, Geraldo Alckmin. À saída de cena de um político comprometido com a reforma agrária, acrescenta-se a mudança da conjuntura econômica. A quebra da paridade real-dólar (ocorrida desde 1999) e a retomada de um ciclo de prosperidade na agropecuária nacional alteram as condições econômicas, outrora ótimas para negociações com os ruralistas. Sem a liderança de Covas e com um cenário de valorização de ativos fundiários, o ritmo de implantação de assentamentos, principalmente no Pontal, re- 
gião de maior impacto da ação reformista do governo paulista, caiu vertiginosamente.

Muda o governador, muda o Itesp. Não só houve alteração na sua diretoria executiva, posto mais importante do órgão, como também muitos técnicos, que ocupavam cargos de confiança na Instituição, foram exonerados. Além disso, o processo de constituição de uma Fundação própria, como personalidade jurídica do órgão de terras, planejado na gestão Covas e concluído na primeira gestão Alckmin (2000-2002), teve percalços que repercutem até os dias de hoje ${ }^{14}$.

Quase como um projeto interrompido, a política de assentamentos implementada por Covas sofreu reveses e inflexões visíveis. No campo das ações para o desenvolvimento dos projetos de assentamentos, a mais visível dessas inflexões certamente foi a elaboração e publicação das portarias (em 2002 e 2003) que autorizam as "parcerias" dos assentados com empresas agroindustriais, o que abriu o ciclo de cultivo de cana-de-açúcar para fornecimento às usinas nos assentamentos ${ }^{15}$.

De uma "perda de fôlego" durante a gestão Alckmin (2001-2006), a situação do órgão de terras estadual teria chegado, durante a gestão Serra (2007-2010), a uma completa exaustão, uma quase letargia ${ }^{16}$. Afora ações pontuais, a grande questão levantada pelos dois últimos governos estaduais teria sido a defesa das portarias que regulamentaram a integração problemática com a agroindústria sucroalcooleira (Barone, Ferrante e Bergamasco, 2008), talvez o grande "projeto" do Itesp para o desenvolvimento dos assentamentos. No mesmo período, tiveram início os processos de licenciamento ambiental dos PAs, sem dúvida uma necessidade, cobrada pelo Judiciário, a partir da intervenção do Ministério Público e, ao mesmo tempo, um obstáculo, haja vista a demora na obtenção das licenças e os consequentes prejuízos no encaminhamento de projetos produtivos nos assentamentos.

O resultante esvaziamento teria como componente especificamente político uma orientação governamental, na qual assentar não seria uma solução. Além de opiniões colhidas junto aos técnicos, corroboram para essa tese a desvalorização profissional do quadro técnico ${ }^{17}$ e a indicação, para diretor executivo do Itesp, de um jovem egresso da carreira jurídica, com atuação partidária na capital paulista e sem um passado ligado à temática da reforma agrária. 
Destaca-se, neste último período (novo governo Alckmin, 2011-2014), a perspectiva de retomada de alguma iniciativa do Itesp, como a divulgada proposta de direcionar, nos moldes do PAA, a produção dos assentamentos para as cozinhas das unidades prisionais, bastante numerosas no Pontal do Paranapanema ${ }^{18}$. A perspectiva de reversão da desvalorização do órgão e de seu quadro técnico, com o retorno de um governador que, em alguma medida, deu continuidade à política de Mario Covas, ainda é uma incógnita.

A expectativa, no entanto, existe. Isso fica transparente em depoimentos colhidos junto aos funcionários, que em seus depoimentos citam, recorrentemente, o novo diretor executivo do Instituto. Desde a desincompatibilização de Serra para concorrer à presidência, no segundo semestre de 2010, assumiu a gestão do Itesp um funcionário da estrutura do órgão, morador da região de Andradina, no noroeste do estado, com perfil muito próximo à média dos técnicos do Itesp. Esse "jeitão de técnico" tem funcionado como um recurso para esse agente que, de interino (em 2010), foi confirmado como diretor executivo pelo governador Alckmin, em 2011. A duração do capital político desse novo diretor do Itesp é uma questão que depende da retomada efetiva de um protagonismo perdido em todo o estado nos últimos anos.

\section{O PAPEL DO INCRA: DE COADJUVANTE A PROTAGONISTA?}

Se na trajetória do Itesp, ao período de grandes realizações do governo Covas se seguiu um esvaziamento político do órgão de terras estadual nos governos Alckmin e Serra, seu correspondente federal, o Incra, ganhou, notadamente a partir da posse de Lula (2003), um protagonismo que nunca teve no contexto paulista. Talvez até porque a política da gestão Covas, de arrecadação negociada das terras do Pontal, tivesse atendido bastante bem às demandas por assentamentos durante os anos Fernando Henrique, o órgão de terras federal teve um papel discreto, como mero repassador de recursos, e coadjuvante no cenário da reforma agrária em São Paulo nesse período.

No entanto, na medida em que o Incra também assentou muitas famílias entre os anos 1980 e 1990, o órgão se portou sempre como uma agência ausente do cotidiano e das necessidades dos assentados. Até porque a ATER, durante esses anos, era sempre prestada pelo serviço estadual, seja ele o Departamento de Assentamento Fundiário (órgão ligado à Secretaria Estadual da Agricultura, antecessor do Itesp) ou 
Itesp (a partir dos anos 1990). Nesses assentamentos federais, por mais que os técnicos de campo do Itesp tivessem sensibilidade e comprometimento, todo o encaminhamento administrativo para benfeitorias nas áreas comunitárias, assentamento de famílias em lotes vagos ou notificação de ocupação irregular, cabia ao Incra, cujos técnicos eram lotados em São Paulo. A distância geográfica e a postura meramente burocrática, sempre foram criticadas como geradoras de evidentes prejuízos para a celeridade dos processos relativos aos PAs, mesmo os mais urgentes.

No período mais recente, correspondente aos dois governos Lula (2003-2010), o Incra, desde há muito criticado como uma autarquia problemática na estrutura do governo federal, passou a ter mais dinamismo, sobretudo no contexto paulista. A nomeação de um militante do PT para a superintendência de São Paulo levou a que um grupo defensor da reforma agrária assumisse a condução do órgão, dando-lhe mais consistência política ${ }^{19}$. A tentativa de diálogo e busca de apoio junto a diferentes segmentos que gravitam em torno da problemática da reforma agrária em São Paulo foi a tônica dessa gestão, que tentou imprimir uma face mais parceira nas negociações com os movimentos sociais e sindicais rurais, ONGs e as universidades.

Duas estratégias complementares foram desenvolvidas pelo Incra, nesse período. Buscando superar o distanciamento crônico das populações diretamente beneficiárias de suas ações, o Incra passa a gerir uma política de descentralização, com a abertura de escritórios técnicos em várias regiões do estado. Dessa forma, se não pudessem atender plenamente demandas como as da ATER, os agentes lotados nas regiões poderiam estreitar o diálogo com os grupos mais organizados dos assentados e seus representantes/mediadores.

Foi assim que, claramente, o Incra pôde "tomar pé" de situações problemáticas nas duas regiões analisadas. No caso do Pontal, a instalação de um escritório no município de Teodoro Sampaio (um dos primeiros da "descentralização") possibilitou mais interlocução com o MST. Nessa região, o Incra atuou, num primeiro momento, na busca por reativar o projeto da COCAMP, iniciativa de cooperativismo idealizado pelo MST para os assentados do Pontal, cuja planta agroindustrial não chegou a ser concluída devido a uma série de irregularidades na sua gestão ${ }^{20}$. 
Já em Araraquara, a bastante polêmica implantação de canaviais no território do assentamento Bela Vista do Chibarro, iniciativa de assentados e usinas, por fora de qualquer regulamentação (posto não terem vigência, para PAs do governo federal, as normativas editadas pelo Itesp nas Portarias de 2002), torna-se a preocupação primeira dos agentes do Incra, que passam a dialogar com diferentes mediadores, representados pelos grupos de assentados, Federação dos Empregados Rurais Assalariados do Estado de São Paulo (Feraesp), e grupos acadêmicos, na busca de um plano de ação frente ao chamado "arrendamento para a cana" ${ }^{21}$.

A outra estratégia mostrou-se bem mais complexa e problemática. Para reestruturar o órgão do ponto de vista dos seus recursos humanos, além da realização de concursos públicos para contratação de funcionários, o Incra lançou mão de editais de contratação de entidades sociais formadas por coletivos de técnicos. Essas "organizações sociais" - sobretudo cooperativas de técnicos - passaram, então, a fornecer uma importante parcela de agentes ao Incra, numa modalidade de terceirização que, como face mais polêmica, acabava por contemplar grupos militantes, articulados em organizações que passaram a gerir, por exemplo, toda a política de ATER/ATES do Incra.

Num movimento de mão-dupla, o Incra teria incorporado, não somente as pautas de diferentes organizações, mas os próprios militantes, tornados funcionários terceirizados do governo federal. Por outro lado, a possibilidade de distribuir postos de trabalho, mais a disponibilidade de recursos e equipamentos de apoio como escritórios, veículos e telefonia móvel, anunciava um virtual aparelhamento indireto do órgão, através das equipes terceirizadas. Esse arranjo foi politicamente buscado, de forma a atender o conjunto de forças sociais de trabalhadores rurais do Estado.

Além desse virtual "aparelhamento", o patrocínio de programas de formação técnica e incentivo à produção também foi um instrumento largamente utilizado para a construção de compromissos das organizações de trabalhadores e demais grupos de pressão que gravitam em torno desse campo com o governo Lula e suas políticas (em primeiro lugar), mas também com o grupo gestor do Incra. O caso mais emblemático dessa prática, bem como de seus limites, estampou as páginas dos jornais em meados de junho de 2011, já no governo Dilma, quando José Rainha Júnior - o conhecido líder dos sem-terra de São Paulo - foi 
preso numa operação da Polícia Federal, acusado de desvio de recursos federais liberados para o desenvolvimento de um grande projeto de produção de oleaginosas para a fabricação de biodiesel. No mesmo dia da prisão de Rainha, o superintendente do Incra /SP teve que depor numa Delegacia da Polícia Federal, atendendo a um procedimento judicialmente sancionado.

Esse imbróglio político, tornado caso de polícia, não só marcou o fim da gestão desse superintendente, como revelou os limites dessa ação política, não só do ponto de vista de sua legalidade ${ }^{22}$, como também da sua legitimidade. Isso porque, mesmo tendo certa prodigalidade na distribuição de recursos para diferentes organizações e movimentos sociais, a atuação do Incra, entendida como as decisões e metodologias políticas de seu núcleo dirigente no estado, não logrou um consenso duradouro.

Diferentes determinantes podem ter concorrido para esse consenso frágil, junto aos movimentos de trabalhadores rurais. Excluindo eventuais idiossincrasias dos dirigentes do órgão, em seus embates com lideranças de trabalhadores, o contexto de disputa muito virulenta por espaço, tanto no partido (PT) quanto nas instâncias de maior poder do governo federal sempre colocou grupos ideologicamente muito próximos, em tensão permanente, quando não em uma guerra política pública e aberta ${ }^{23}$. Essa disputa por influência acabou por gerar certo isolamento da superintendência de São Paulo na estrutura da autarquia federal do Incra.

Outro determinante, mais evidente, foi a transferência da arena de atuação dos movimentos sociais e organizações de trabalhadores rurais, da rua para os gabinetes. $O$ amplo recrutamento desses setores populares pelo governo federal - celebrado, num primeiro momento do governo Lula, como "nosso governo" - levou as tensões, contestações e resistências dessas frentes de mobilização para dentro das instâncias governamentais. "Queimar o companheiro", que assumiu posto em alguma instância governamental, passou a ser parte recorrente e fundamental da estratégia de pressão - mais do que as mobilizações públi$\operatorname{cas}^{24}$.

Essa internalização dos conflitos foi marca da gestão Lula, verdadeira contraface de certa "domesticação" do poder contestador dos movimentos sociais. No caso do Incra, a tentativa de cooptação das organizações de trabalhadores cumpriu parte da estratégia de internalizar os 
conflitos no governo Lula, mas não blindou especialmente o grupo que operava essa política.

É de difícil avaliação a relação entre as organizações dos sem-terra e o governo Lula - extensivamente para o governo Dilma. No caso do MST, particularmente, há um desafio de caminhar "no fio da navalha" no tocante ao apoio político ao PT e à crítica sobre as decisões práticas do governo que tem o PT como principal partido (Barone, 2011). O risco de cooptação do movimento como força de apoio ao partido e ao governo é constante, notadamente junto às direções estaduais, como no caso de São Paulo.

Diante desse desafio sensibilíssimo, outro determinante fundamental na instabilidade na gestão do Incra, sem dúvida, foi o ônus de gerir uma política de assentamentos que acumulou frustrações em seus números, ao menos para a parcela mais mobilizada dos trabalhadores sem-terra (Oliveira, 2006). Mesmo reconhecendo um descenso das lutas e da pressão pela distribuição de terras, sobretudo em função da conjuntura econômica mais afluente dos últimos anos, é fato que mobilizações aconteceram ao longo do período Lula que, praticamente, coincide com o período de gestão dessa superintendência.

Essa demanda, diminuída a montante, recebeu atendimento por parte do governo federal e do Incra, seu representante, mas não da forma mais abrangente, o que manteve vivos, durante esses oito anos, pressões e discursos contrários à atuação do órgão. O Incra continuou avaliado como moroso/burocrático e pouco interessado no atendimento aos sem-terra, quando não (na opinião dos setores mais radicalizados, que romperam com Lula), mero implementador de uma política contrarreformista advinda de Brasília (Oliveira, 2006).

Nesse quesito, no entanto, é importante destacar as alternativas e os resultados das ações do órgão federal no assentamento de famílias no Estado de São Paulo, até porque, no mesmo período, a atuação do Itesp foi mais tímida ainda. No contexto do Pontal do Paranapanema, por exemplo, a equipe do Incra buscou fórmulas para que a autarquia federal pudesse implantar alguns assentamentos naquela área, cuja situação de irregularidade fundiária sempre elevou o Itesp à condição de protagonista maior ${ }^{25}$. Assim, no Pontal, o Incra assentou centenas de famílias, superando os números do ITSP no mesmo período. Dando continuidade a uma grande ação de reconhecimento de áreas improdutivas, realizadas ainda no final do governo FHC, o Incra teria sua 
ação mais intensa na região noroeste do estado na região de Andradina, mais ao norte do Pontal.

Além disso, é digna de nota a busca por alternativas que gerassem o atendimento à demanda dos sem-terra, mesmo considerando-se as limitações econômicas e políticas desse período ${ }^{26}$. O exemplo mais evidente disso foi o assentamento de milhares de famílias em projetos especiais, como os Projetos de Desenvolvimento Sustentável (PDS), estratégia de assentamento originalmente concebida para atender às populações tradicionais de castanheiros e seringueiros da Amazônia. Ações judiciais tematizando danos ambientais por parte da agroindústria sucroalcooleira possibilitaram a implantação, na região de Ribeirão Preto, de dois PDS. Essa modalidade se repetiu, garantindo o assentamento de sem-terra no sul do estado (Vale do Ribeira) e também no Pontal do Paranapanema. Observa-se que, sobretudo no noroeste do estado (região de Andradina), a ampliação do número de assentamentos garantiu uma base popular bastante estável ao grupo que dirigiu o Incra no período recente. Na região de Ribeirão Preto (próxima a Araraquara), o segmento do MST que liderou os sem-terra e, atualmente, dirige boa parte dos assentados nos Projetos de Desenvolvimento Sustentável sempre teve uma forte ligação com o grupo gestor do Incra.

Contudo, no conjunto de forças políticas que mobilizam os sem-terra, destacou-se como aliado do Incra, sobretudo no segundo período do governo Lula (2007-2010), a fração do MST sob liderança de José Rainha Jr., há anos desligado da estrutura formal da organização. Essa citada preferência pelo "dissidente" Zé Rainha opôs o MST do Pontal ao Incra. Divergências com relação ao andamento dos projetos e uma citada recusa, por parte do Incra, de um grande projeto do MST na regiãoque funcionaria como um contraponto à liderança de Rainha -, teriam sido outros elementos que levaram a que essa relação ficasse completamente esgarçada nos últimos anos do governo Lula ${ }^{27}$.

Além disso, o apoio da regional Pontal do MST à ocupação de uma fazenda da Cutrale, no município de Iaras, em 2009, acabou por ser o alegado motivo da discórdia e distanciamento entre o movimento da região e o Incra. Bastante divulgada pela mídia - em notícias que mostraram a derrubada de pomares de laranja da fazenda -, essa ação, que objetivaria pressionar o governo para a recuperação de terras públicas naquela região, numa área em litígio por ser uma propriedade original 
da União, conhecida como Núcleo Colonial Monção, acabou por reativar uma campanha pública contrária ao MST, retomando as conhecidas acusações de "baderneiros", "atrasados" e contrários à produção ${ }^{28}$.

Essa rápida panorâmica sobre as conjunturas dos dois órgãos de terras se fecha no ano de troca de governos (2011), embora não dos partidos que encabeçam as coligações governantes (PT e PSDB, nas esferas federal e estadual, respectivamente). Os impasses com relação a mudanças na atuação dessas duas agências públicas, que exercem importante papel de mediação junto à população assentada, estão fortemente condicionados às novas direções desses institutos, assim como à prioridade dada, pelos governantes, às temáticas relativas ao assentamento de novas famílias e às políticas de apoio às experiências de assentamentos rurais já em desenvolvimento.

\section{IMPASSES DOS MEDIADORES POLÍTICOS: COOPTAÇÃO E ESVAZIAMENTO}

Sem dúvida, o MST é a principal referência em termos de organização de luta pela reforma agrária no Brasil. Para além de uma multiplicidade de movimentos que se empenham na luta pela terra, sobretudo em atuação no Pontal do Paranapanema (Lima, 2006), também é objeto de avaliação, neste trabalho, o movimento sindical rural, notadamente a Feraesp, entidade bastante ativa na região de Araraquara ${ }^{29}$. As trajetórias dessas organizações, embora tendo origens e estratégias diferentes nos anos 1980-1990, coincidem em postura frente ao estado no período Lula (2003-2010).

Ensaiando uma avaliação dessa relação entre os movimentos, como atores políticos, frente ao arranjo hegemônico que dirige o Estado brasileiro, temos que esta se torna profundamente mais complexa com a chegada ao poder político da frente liderada pelo PT, em 2003. A mais óbvia das observações nesse campo diz respeito à inflexão adotada pelas organizações, notadamente o MST. Embora com marchas e contramarchas, fica evidente, ao observarmos o período todo do governo Lula, que o MST adotou "um lado" na divisão das forças hegemônicas da política brasileira. No entanto, essa trajetória merece ser revista. De um tom celebrativo comedido, do tipo "chegamos ao governo e não ao poder" - depoimentos de lideranças logo após a eleição - e da análise de que o governo Lula era um "governo em disputa" (reiterada em entrevistas de lideranças a importantes órgãos de imprensa ao longo de 2003), 
percebe-se, claramente, a elevação do tom crítico a partir da não aprovação, pelo Governo, da proposta do II Plano Nacional de Reforma Agrária, elaborada sob a coordenação de Plínio de Arruda Sampaio, ainda no final de 2003 (Branford, 2010; Oliveira, 2006).

Em 2004, parecia desenhar-se, no cenário político brasileiro, uma postura que, a partir da frustrante situação de 2003, dominaria a relação entre Governo e as organizações de trabalhadores rurais em tela neste trabalho (Feraesp e MST). Assiste-se a uma tensão crescente no diálogo, acompanhado de um acirramento dos conflitos no campo, a partir do aumento das ações de ocupação, que sempre foram a marca registrada do MST.

Tal postura, derivada da frustração das organizações e de parte da esquerda que ajudou a eleger Lula, era esperada, dadas as decisões que o governo federal tomou, tanto com relação à temática agrária, quanto com relação à gestão macroeconômica do Estado brasileiro, reeditando a linha tida como "neoliberal" do governo anterior. No caso específico da Feraesp, cuja natureza institucional a faz especial porta-voz dos interesses dos assalariados rurais, cita-se, como agravante nesta conjuntura de distanciamento, a discussão de Medida Provisória que "flexibilizaria" o contrato de trabalho do assalariado rural sazonal, considerada uma "burla" da Consolidação das Leis do Trabalho (CLT) para o segmento dos proletários do campo ${ }^{30}$.

Porém, a conjuntura que se desenvolveu em 2005 teve um efeito fortíssimo sobre as ações e posturas políticas desses mediadores, no contexto de sua relação com o governo federal. Pesa sobre tais ações a eclosão da principal crise do governo Lula, a denúncia do chamado "mensalão", que seria uma prática adotada pelo Executivo para aliciar uma base governista totalmente fisiológica. A ameaça de um processo por corrupção ativa, que poderia chegar até ao impedimento do presidente Lula, fez ocorrer um novo alinhamento dos movimentos, agora sob pressão de um "golpe da direita".

Enquanto setores da esquerda, que atuavam no meio sindical e, inclusive, detinham mandatos eletivos pelo PT, rompem formalmente com o partido ${ }^{31}$, o MST acaba por se tornar um fiador popular de Lula, uma espécie de força de dissuasão política, ao lado da União Nacional dos Estudantes (UNE) e CUT, (à qual a Feraesp é filiada). Inúmeras foram as ameaças não cumpridas de mobilizações massivas, de rua, de ambos os lados, detratores e defensores do governo. No campo da oposi- 
ção capitaneada por PSDB e PFL/DEM, evidenciou-se a completa falta de apoio junto aos setores mais organizados das classes populares, justamente aqueles que sempre apoiaram Lula. No campo hegemonizado pelo Governo, por sua vez, a simples referência a possíveis manifestações de massa, mas sempre a partir de declarações das lideranças políticas das organizações populares (MST inclusive), bastou para definir a vitória de Lula nessa "batalha política nas ruas que efetivamente não ocorreu" (Barone, 2011).

Uma postura pragmática foi, paulatinamente, assumida e ganhou força desde 2005. A vitória de Lula em 2006, com apoio político do MST velado no primeiro turno e explícito no segundo-, teria ajudado a consolidar o que passou a ser definido como "lulismo" (Singer, 2009), que não deixa de ser, de uma maneira atualizada, um novo populismo. $\mathrm{O}$ certo é que, enquanto a Feraesp aderiu de forma mais institucional ao governo (via CUT), o MST parece ter mudado substancialmente sua forma de agir frente ao Estado, e ao governo Federal, sem uma reflexão crítica sobre essa relação ${ }^{32}$.

Notou-se que, para além da adesão institucional via CUT, a Feraesp também desenvolveu relações com distintas instâncias governamentais. Para além de convênios mediados pelo Incra e MDA, objeto especial de "patrocínio" governamental no caso do MST, a Feraesp executou uma estratégia sindical de pactuação com o setor sucroalcooleiro ${ }^{33}$, o que lhe garantiu apoio no desenvolvimento de vários programas de capacitação/requalificação, além do esboço de um grande projeto de produção de alimentos nos assentamentos para fornecimento aos refeitórios das usinas e destilarias, uma espécie de Programa de Aquisição de Alimentos (PAA) privado.

Numa escala mais próxima da realidade dos assentamentos, ambas as organizações estimularam a formação de entidades cooperativas, cujos objetivos podem variar, embora sua gestão normalmente acabe por ficar fortemente dependente da conjuntura e da tomada de decisões dos movimentos em relação aos governos. Tanto no Pontal do Paranapanema quanto em Araraquara, ao lado de iniciativas associativas mais pulverizadas e, às vezes, de orientação contrária aos principais mediadores (governos e movimentos), MST e Feraesp investiram na estruturação de cooperativas, cujas trajetórias sofreram um declínio muito rápido, às vezes sequer promovendo alguma mudança na realidade dos produtores assentados. 
Em Araraquara, a Feraesp chegou a apoiar ativamente a formação de uma grande cooperativa, no início da década de 1990, a Cooperativa dos Assentados na Reforma Agrária da Região de Araraquara (COAPRA), sediada no PA Bela Vista do Chibarro, cujo parque de máquinas não logrou atender aos seus associados no preparo das terras gerando, inclusive, uma inadimplência que a levou ao seu completo imobilismo (Barone, 2002). Esse fracasso acabou por fortalecer, em grande parte dos assentados, uma tendência à adesão da proposta de plantio de cana para fornecimento agroindustrial, patrocinada principalmente por uma associação dita "independente" (Barone e Ferrante, 2007).

A já discutida retomada das iniciativas do Incra nesse PA enfrentou esse grupo organizado de assentados, gerando inclusive ações de despejo (Barone, Ferrante e Bergamasco, 2008; Ferrante e Barone, 2011). Como uma estratégia alternativa, a FERAESP patrocinou a formação de outra cooperativa, com escopo mais abrangente, já que não atende somente a assentados: a Unicampo. A partir de parcerias com o Incra, a Unicampo tem desenvolvido atividades de capacitação em agroindústria familiar e promovido microprojetos produtivos, sobretudo envolvendo grupos de mulheres nos assentamentos de Araraquara.

No Pontal do Paranapanema, dados o patamar de desenvolvimento regional e a amplitude política e demográfica que os Projetos de Assentamentos exibem, o MST fundou, em 1994, a Cocamp, um ambicioso projeto econômico para os assentamentos (Ribas e Thomaz Jr., 2000). No entanto, a não consecução de seu projeto industrial, aliado a um frustrante estímulo à fruticultura junto aos seus associados (com promessa de compra da produção para a despolpadeira), determinou o esvaziamento da Cocamp. Além disso, a situação financeira dos assentados ficou, em muitos casos, pior.

A importância desse projeto, não só para os assentamentos, mas para toda a região, foi prejudicada pelos inúmeros problemas de gestão da cooperativa. Dependente de recursos oficiais, a Cocamp sofreu com a extinção do Procera ${ }^{34}$, principal fonte de seu financiamento. A partir dos anos 2000, a Cocamp passou, também, a ser investigada pelo Ministério Público por denúncias de desvio de recursos. Atualmente, o processo se encontra parado e parece improvável que o apoio político (e material) dado aos muitos acampamentos e ocupações do MST na região não tenha levado, de alguma forma, a um comprometimento da parte produtiva da cooperativa. Sem dúvida, essa situação cria um im- 
passe que se prolonga até os dias de hoje. A cooperativa não concluiu nenhuma das obras de instalação industrial, imobilizando um alto capital sem qualquer perspectiva de retorno.

A retomada das atividades da cooperativa continua incerta, mesmo após tentativas envidadas pelo Incra/SP no primeiro governo Lula (2003-2006). No segundo período Lula, essa cooperativa passou a ser mais um motivo de afastamento entre MST e Incra. Para o órgão federal, a cooperativa encontrou dificuldades em receber verbas oficiais devido aos processos judiciais que envolvem a sua gestão. Para lideranças do MST, o Incra abandonou a luta política por esse projeto, em favor de ações mais pulverizadas e de maior visibilidade. O já citado apoio ao projeto de produção de biodiesel na região, defendido pela dissidência liderada por "Zé Rainha", também afastou a coordenação regional do MST da órbita do Incra. Em acréscimo, temos que o fracasso do projeto do biodiesel, embora haja ainda alguns cultivos experimentais, mas sem qualquer perspectiva de retorno econômico ${ }^{35}$, só reforça a perda de legitimidade também da dissidência, lançando os assentamentos num vazio de representação política mais coesa.

\section{CONCLUINDO: POR UMA NOVA ESTRATÉGIA DE DESENVOLVIMENTO}

O programa de assentamentos rurais, iniciado em São Paulo no empuxo da transição democrática e, no governo Montoro, antecipando o próprio I PNRA, chega à segunda década do século XXI com uma população beneficiada estimada em mais de 15 mil famílias. Sua gestão, no entanto, mostra-se extremamente difícil, não só pela exiguidade de terras legalmente aptas para destinação aos sem-terra, motivo muitas vezes alegado frente aos trabalhadores. As dificuldades de inserção plena e autônoma desses "novos agricultores familiares" nos circuitos econômicos regionais, altamente oligopolizados, sem dúvida são relevantes, embora pese, a favor desses agentes, a criação de um polo institucional de demanda por alimento, materializado nos programas do governo federal (PAA, PNAE etc.). Resta, no entanto, uma deficiente assistência técnica a esses produtores, bem como uma ausência de estratégia clara, minimamente consensual e de médio e longo prazos para incrementar o desenvolvimento dos Projetos de Assentamento.

Essas últimas dificuldades a serem superadas dizem respeito, fundamentalmente, aos mediadores aqui discutidos (agências estatais e organizações de trabalhadores). Mais de 25 anos após o I PNRA, um ser- 
viço de assistência técnica aos assentados da reforma agrária se mostra extremamente dependente do governo de turno, bem como das injunções político-partidárias por ele geradas. O Itesp, que foi importantíssimo no processo de luta pela terra no Pontal do Paranapanema, sofreu um esvaziamento de suas funções nos períodos mais recentes. Esse órgão, por outro lado, conta com um quadro de assistência técnica que, se não é suficiente numericamente, tem maior estabilidade e experiência, pois são todos funcionários concursados. No caso do Incra, a contratação de organizações para prestar assistência técnica (o órgão público em si não pode fazer ATER), mostra-se muito dependente das mudanças conjunturais de sua superintendência, além de sofrer forte influência político-partidária.

Com relação às organizações de trabalhadores (MST e Feraesp, aqui estudadas), estas padecem de uma falta de visão de longo alcance. Por trás dos discursos mais ou menos radicalizados (como a defesa da agroecologia nos assentamentos), pouco é feito no sentido da construção de consensos e disseminação de práticas que facilitem a vida dos assentados e apontem para um "Norte" claro. Observou-se que, sobretudo no período do governo Lula, as oportunidades de mediar recursos (para projetos produtivos ou "de formação") foram, na maioria das vezes, subterfúgios para fortalecer as estruturas políticas dessas organizações, não restando muito em termos de mudança no contexto dos assentamentos.

Esses dois tipos de agências se complementam, na medida em que, não havendo uma pressão específica por parte dos movimentos, os órgãos públicos não se sentem cobrados para desenvolver programas neste sentido. No caso do Incra, uma constatada capacidade de propor projetos e oferecer recursos, algo em si positivo, pode causar mesmo uma inversão no sentido dessa pressão. Isso, somado ao sensível controle político partidário do órgão, gera uma certa letargia nas organizações de trabalhadores, com tendência a diminuir sua criatividade propositiva, empurrando-as para a posição de meras forças auxiliares do governo do PT, dentro de uma estrutura populista (Barone, 2011). Os assentados, por seu lado, fortemente dependentes das iniciativas desses dois conjuntos de mediadores, carecem de expressar suas demandas específicas frente essas agências. Além disso, em se consolidando essa letargia propositiva das suas organizações representativas, enfrentarão dificuldades enormes para buscar uma estratégia que os coloquem em posição menos subalterna diante do estado. Tornar essas agências 
mais orgânicas dos seus interesses reais parece ser um desafio dos assentados, para além da mera pressão por mais recursos, discurso mais comum quando se tematiza o assunto. Sem isto, a perspectiva de pensar em outro modelo de desenvolvimento para os assentamentos corre o risco de permanecer no campo das utopias e virtualidades.

(Recebido para publicação em março de 2012)

(Reapresentado em maio de 2012)

(Aprovado para publicação em julho de 2012)

\section{NOTAS}

1. Referimo-nos à trajetória de pesquisa da equipe do Núcleo de Pesquisa e Documentação Rural (Nupedor), fundado em 1987, cujos sucessivos projetos tematizam a política de assentamentos rurais no Estado de São Paulo. Há cerca de 20 anos, pesquisas desse Núcleo, apoiadas pelo CNPq, estudam prioritariamente o desenvolvimento dos assentamentos rurais nas regiões de Araraquara e do Pontal do Paranapanema.

2. Entendemos por integração uma situação na qual o assentado tem, por meio de contrato ou acordo tácito, uma relação direta com alguma agroindústria, enquanto fornecedor de matéria-prima (cana, frango, leite) que será entregue à empresa e por ela processada.

3. Destacam-se, como exemplos dessas novas medidas institucionais, o Programa de Aquisição de Alimentos (PAA) e o Programa Nacional de Alimentação Escolar (PNAE), ambos geridos pelo governo federal, que fomentam a produção dos assentamentos garantindo a sua venda.

4. Respectivamente, Cooperativa dos Assentados de Reforma Agrária do Pontal do Paranapanema, Cooperativa de Produção de Biodiesel do Oeste Paulista e Cooperativa Unificada dos Trabalhadores do Campo.

5. Existe um outro PA no munícipio, o de Bueno de Andrade, com trinta famílias, cuja origem é praticamente idêntica ao do núcleo VI da Monte Alegre

6. Ocupada por meio de sucessivas grilagens de terras, a região extremo-oeste de São Paulo, conhecida como Pontal do Paranapanema, concentrou conflitos pela posse da terra. Durante os anos 1990, a partir da atuação do MST na região, milhares de sem-terra foram assentados na região (Leite, 1998; Fernandes, 1996).

7. Nesta parte do texto, sempre que utilizarmos a sigla INCRA estaremos nos referindo à Superintendência Regional 08 (SR-8) do Instituto de Colonização e Reforma Agrária, que corresponde à jurisdição do Estado de São Paulo - com exceção de menções explícitas no texto em que nos referimos à estrutura nacional do órgão.

8. Teremos, ao término do atual período de governo (2011-2014), 20 anos de governos peessedebistas em São Paulo. 
9. Cita-se que no programa de governo da gestão Alckminn (2003-2006), havia referência à política de assentamentos do estado, inclusive com uma meta, específica para 0 Pontal do Paranapanema, de 1.200 novas famílias assentadas. No programa de gestão do governo Serra (2007-2010) não há menção aos assentamentos (fala-se de regularização fundiária no Pontal) nem citação de metas para assentar sem-terra no estado.

10. Em depoimentos colhidos informalmente, técnicos mais antigos do Itesp fizeram reiteradamente esta avaliação. Numa ocasião, inclusive, comentou-se que o governador José Serra estaria sendo fiel à sua opinião, manifestada anos atrás, de que seria mais viável economicamente "dar um táxi" para cada trabalhador rural, em vez de assentá-los em alguma terra.

11. A âncora verde do real foi justamente a facilidade, ocasionada pela paridade cambial imposta nos primeiros anos da nova moeda, na importação de alimentos para suprir o mercado interno, segurando qualquer tendência de alta da inflação motivada pela crescente demanda de bens da agropecuária.

12. Corria, no início da década de 1990, uma ação popular reivindicando do estado a tomada de posse das áreas devolutas griladas durante décadas na região do Pontal. Essa iniciativa da sociedade civil, liderada pela Comissão Pastoral da Terra, não prosperou, embora tivesse motivado a Procuradoria do Estado a articular processos de averiguação da legitimidade dos títulos fundiários na região (Fernandes, 1996). Esses processos se arrastam, desde então, com algumas sentenças definitivas a favor do estado, saindo já nos primeiros anos do novo século.

13. Covas, durante seu mandato de senador no período Constituinte (1987-1988), foi líder da bancada da reforma agrária, o grupo de parlamentares que defendiam cláusulas constitucionais pró-distribuição de terras no país.

14. Cita-se o questionamento judicial dos concursos para técnicos da nova fundação e a não implementação de plano de carreira dos funcionários, elaborado ainda sob a diretoria executiva nomeada por Covas.

15. Cita-se que, durante a gestão Covas, a diretoria executiva do Itesp se mantinha contrária às diferentes propostas de "consórcio" para plantio de cana nos assentamentos da região de Araraquara (Ferrante e Santos, 2003). Por outro lado, a partir de pressões da base política do governador Alckmin, nessa mesma região, a nova diretoria executiva do órgão estabeleceu duas portarias que regulamentaram as "parcerias negociais" entre assentados e usinas e destilarias.

16. Segundo avaliação de técnicos do próprio Itesp.

17. Além do registro de muitos técnicos que migraram do Itesp para o Incra de 2006 a 2010, era comentado, de forma jocosa e pelos próprios técnicos, que os funcionários do Itesp ficavam no escritório "buscando informações sobre concursos públicos para prestar".

18. O Programa Paulista Agricultura de Interesse Social (PPAIS) foi amplamente divulgado no primeiro ano da gestão Alckmin (2011), com implantação prevista para 2012.

19. Essa gestão do Incra, além do PT no seu núcleo dirigente, teve uma forte ligação com a seção paulista da Associação Brasileira da Reforma Agrária (ABRA), ONG com grande tradição na pressão pela reforma agrária no país.

20. Particularmente essa problemática situação da Cooperativa do MST em Teodoro Sampaio, por mais que a proximidade de agentes do Incra tivesse intenção de colabo- 
rar em soluções, mantém-se como um imbroglio praticamente insolúvel. O bloqueio judicial das contas da COCAMP, ainda investigada por malversação de recursos públicos, inviabilizou várias tentativas de recuperação política e econômica dessa organização cooperativa (Ribas e Thomaz Jr., 2000).

21. A execução de ação de despejo judicial, como resposta política contrária à cessão de lotes para plantio de cana agroindustrial, foi uma realização dos agentes lotados no escritório de Araraquara, ao longo de alguns anos de negociações. Tal ação impactou bastante os moradores do assentamento que passaram a buscar o rompimento dos contratos de fornecimento de cana às Usinas (Ferrante e Barone, 2011).

22. Existem ações judiciais questionando a regularidade, dentre outras coisas, dos contratos de terceirização.

23. As disputas por espaço e por concepção de políticas públicas - quase sempre eivadas de disputas entre grupos de militantes - marcou diferentes áreas do governo federal sob a presidência de Lula. Cita-se, especialmente, o divórcio entre a estrutura do Ministério do Desenvolvimento Agrário (MDA) e o Incra, que é uma autarquia formalmente submetida ao MDA, mas com uma estrutura independente e um tempo de existência de várias décadas.

24. Nos primeiros meses da gestão Dilma (2011), em depoimento, colhido como desabafo, um agente do núcleo político do Incra se queixou de que os setores do MST que faziam forte campanha pela substituição do superintendente haviam sido contemplados com ações do órgão. Se esse depoimento demonstra a fragilidade do grupo, é eloquente também na revelação de que a contestação passou a existir nos corredores do governo e do partido, "queimando" a figura do superintendente.

25. Tratando-se de terras devolutas, a competência jurisdicional para sua arrecadação e destinação aos trabalhadores sem terra é do governo estadual, através de seu órgão de terras, o Itesp.

26. Talvez a mais importante ação do órgão federal no período foi atuar de forma mais eficiente, sobretudo para garantir uma maior celeridade no processo de liberação dos primeiros financiamentos aos novos PAs (Silva, 2011), verdadeiro gargalo no desenvolvimento socioeconômico dos assentamentos ao longo de todo o período iniciado com a Nova República.

27. Cita-se que a regional do MST do Pontal se posicionou publicamente contra a direção do Incra no início de 2011, inclusive com ocupação do escritório regional do órgão (em Teodoro Sampaio) para "exigir a saída do superintendente".

28. Esclarece-se que foi dessa superintendência do Incra em análise a iniciativa de mover ação judicial para reaver essas terras da União, em processo que ainda se encontra em andamento. A ocupação da fazenda da Cutrale em 2009, com documentada derrubada de pomares da empresa, foi também censurada pela direção do Incra, que viu nela uma manobra atabalhoada, que mais atrapalhou do que ajudou a luta pela terra naquela região.

29. Formada em 1989 como dissidência da estrutura da Confederação Nacional dos Trabalhadores na Agricultura (Contag), a Feraesp, desde seu surgimento, atua promovendo a luta pela reforma agrária, inclusive com ocupações, concentrando suas ações na região de Araraquara (Ferrante, 1992).

30. Trata-se da MP 410, efetivamente editada em 2007, que criou um tipo de "contrato de trabalho rural por pequeno prazo", incidente sobre os "safristas", uma categoria de 
assalariados rurais sazonais, como os cortadores de cana ou apanhadores de café ou laranja, base dos sindicatos ligados à Feraesp.

31. A linha "conservadora" adotada por Lula, mais as denúncias de corrupção, levaram a uma ruptura com o PT de um grupo (do qual fez parte Plínio de Arruda Sampaio, presidente de honra da Associação Brasileira da Reforma Agrária e coordenador do grupo que apresentou a proposta do II PNRA) que trabalhou, então, para a formação do PSOL. Na expectativa desse movimento, por afinidade política-programática, o MST tinha tudo para estabelecer forte relação política com esse grupo, o que não ocorreu nem plano federal, nem no Estado de São Paulo (sobretudo nas eleições de 2010).

32. Especificamente com relação ao MST, esta nova postura acaba por envolvê-lo num obscurantismo que ameaça sua autonomia. A adesão à campanha de Dilma, já no primeiro turno de 2010, não se coaduna com a visão de conjuntura que a organização expressa a partir de sua militância de base. Olulismo parece assombrar o Movimento, a partir de uma política de relação pessoal com lideranças, nomeações de militantes (via estratégia do órgão de terras, conforme visto acima) e uma bem executada ação clientelista, muito mais complexa que a ampliação do "bolsa-família" (Barone, 2011).

33. Trata-se do "Compromisso Nacional para aperfeiçoar as condições de trabalho na cana-de-açúcar", documento de livre adesão (um pacto), elaborado a partir das discussões entre o setor patronal e o dos trabalhadores ligados ao setor sucroalcooleiro e assinado em julho de 2009 por vários Ministérios do governo federal, a União da Indústria de Cana-de-Açúcar (Unica), representando o setor patronal, a CONTAG e a Feraesp (representando o setor dos trabalhadores).

34. Programa Especial de Crédito da Reforma Agrária, principal programa de financiamento de investimentos nos assentamentos, extinto em 1999.

35. Cita-se que acusações de desvio de recursos públicos para o projeto de implantação de cultivos para biodiesel nos assentamentos do Pontal foi o motivo da mais recente detenção de José Rainha Júnior (preso numa operação da Polícia Federal em junho de 2011). 


\section{REFERÊNCIAS BIBLIOGRÁFICAS}

BARONE, Luís A. (1996), Revolta, Conquista e Solidariedade: A Economia Moral dos Trabalhadores Rurais em Três Tempos. Dissertação de Mestrado. Araraquara, FCL/Unesp.

. (2000), “A Assistência Técnica aos Assentamentos Rurais do Estado de São Paulo: da Política Reativa ao Vazio de Projeto". Revista Retratos de Assentamentos, no 7, pp. 47-64.

. (2002), Conflito e Cooperação: O Jogo das Racionalidades Sociais e o Campo Política num Assentamento de Reforma Agrária. Tese de Doutorado. Araraquara, FCL/Unesp.

. (2011), “O MST Frente ao Campo Político-Institucional do Início do Século XXI”. Revista Espaço de Diálogo e Desconexão, vol. 3, no 2, s/p.

BARONE, Luís A. e FERRANTE, Vera L. S. B. (2007), Resistências e Acomodações: As Tensões Sociais Presentes na Constituição dos Assentamentos Rurais da Região de Araraquara/SP. Texto apresentado no XLV Congresso da SOBER (GT: Reforma Agrária e outras políticas de redução da pobreza). Londrina, PR, 22-25 de julho.

. (2010) “As Políticas de Assentamentos em São Paulo: Por um Balanço da Trajetória das Experiências em Distintas Regiões". Retratos de Assentamentos, no 13, pp. 117-136.

e BERGAMASCO, Sonia M. P. P. (2008), Os Parceiros da Cana: Dilemas do Desenvolvimento dos Assentamentos Rurais em São Paulo frente à Produção Agrícola para o Etanol. Trabalho apresentado no 32ㅇ Encontro Anual da Anpocs, Caxambu, MG, 27-31 de outubro.

BARONE, Luís A. et al. (2008), “O Associativismo como Estratégia de Ressocialização e Gestão nos Assentamentos Rurais em São Paulo". Retratos de Assentamentos, no 11, pp. $45-69$.

BRANFORD, Sue. (2010), “Lidando com Governos: O MST e as Administrações Cardoso e Lula", in M. Carter (org.), Combatendo a Desigualdade Social: O MST e a Reforma Agrária no Brasil. São Paulo, EdUNESP, pp. 409-431.

FERNANDES, Bernardo M. (1996), MST: Formação e Territorialização. São Paulo, Hucitec.

FERRANTE, Vera L. S. B. (1992), A Chama Verde dos Canaviais: uma História das Lutas dos Trabalhadores Rurais de São Paulo. Tese de Livre-Docência, Araraquara, FCL/Unesp.

e SANTOS, Marcos, P. (2003), “A Cana nos Assentamentos: Novas Roupagens, Velhas Questões”. Comunicação apresentada no XLI Congresso da SOBER, Juiz de Fora, MG, julho.

FERRANTE, Vera L. S. B. e BARONE, Luís A. (2004), “A Difícil Semeadura: O Trabalho na Terra e a Ressocialização das Famílias Assentadas em Projetos de Reforma Agrária", in R. A. Scopinho et alii (orgs.), Velhos Trabalhos, Novos Dias: Modos Atuais de Inserção de Antigas Atividades Laborais. Fortaleza/São Carlos, EdUFC/EdUFSCar, pp. 112-134. 
(2011), "Parcerias com a Cana-de-Açúcar: Tensões e Contradições no Desenvolvimento das Experiências de Assentamentos Rurais". Sociologias, Ano 13, no 26, pp. 262-305.

LIMA, Edvaldo C. de. (2006), Os Movimentos Sociais de Luta pela Terra e pela Reforma Agrária no Pontal do Paranapanema (SP): Dissidências e Dinâmica Territorial. Dissertação de Mestrado em Geografia, Presidente Prudente, SP, FCT/Unesp.

MARTINS, José de S. (2000), Reforma Agrária: o Impossível Diálogo. São Paulo, EdUSP.

. (2003), O Sujeito Oculto: Ordem e Transgressão na Reforma Agrária. Porto Alegre, EdUFRGS.

OLIVEIRA, Ariovaldo U. de. (2006), A “Não Reforma Agrária” do MDA/INCRA no Governo Lula. Trabalho apresentado na reunião paralela realizada pela Via Campesina durante a Conferência Internacional sobre Reforma Agrária e Desenvolvimento Rural - CIRADR-FAO, Porto Alegre, 7-10 de março.

RIBAS, Alexandre D. e THOMAZ JR., Antonio. (2000), “O Cooperativismo no Raio de Atuação do Movimento dos Trabalhadores Rurais Sem Terra (MST): Uma Contribuição para a Geografia do Trabalho". Geografia em Atos, vol. 1, no 2, pp. 97-118.

SEN, Amartya. (2000), Desenvolvimento como Liberdade. São Paulo, Companhia das Letras.

SILVA, Raimundo. P. (2011) “A Gestão do Incra e a Questão Agrária em São Paulo: Período 2003-2010". Retratos de Assentamentos, no 14, pp. 125-141.

SINGER, André. (2009), "Raízes Ideológicas do Lulismo". Novos Estudos, no 85, pp. 83-102. 


\begin{abstract}
Rural Settlements in São Paulo: Strategies and Mediations for Development
\end{abstract}

Based on research in two areas of the State of São Paulo (Araraquara and Pontal do Paranapanema), this article conducts a critical discussion of the principal mediating agencies in development projects for rural settlements (government agencies and workers' organizations). Based on qualitative research with data collected over an extended period, the study reconstitutes the web of specific social tensions generated by the reciprocal influences between these agencies within the broader context of the political dispensations in the State and Federal governments. The article concludes that these mediations oscillated in recent decades, proving incapable of proposing consistent development projects. This situation results from changes in the political orientation of government administrations and leadership in the workers' organizations, leaving a vacuum in their long-term strategies.

Key words: Rural settlements; mediating agencies; development

\title{
RÉSUMÉ
}

Lotissements de la Réforme Agraire à São Paulo: Stratégies et Médiations pour le Développement

A partir d'une recherche effectuée dans deux régions de l'État de São Paulo (Araraquara et Pontal do Paranapanema), cet article alimente un débat critique sur les deux principales agences médiatrices de projets de développement destinés aux lotissements de la réforme agraire (organes officiels et organisations de travailleurs). A partir d'une recherche qualitative dont les données ont été recueillies sur une longue période, l'article reconstitue la trame des tensions sociales spécifiques engendrées par les influences réciproques que ces agences exercent les unes sur les autres au sein du contexte général des conjonctures politiques propres au gouvernement de l'État et à celui de la Fédération. L'auteur conclut qu'au cours des dernières décennies ces médiations se sont montrées oscillantes, incapables de présenter des projets consistants de développement. Ceci est dû aux changements dans les orientations politiques des gouvernements et dans la direction des organisations, ce qui engendre un vide de stratégies sur le long cours.

Mots-clés: lotissements de la Réforme Agraire; agences de médiation; développement 